\title{
Características físico-química e microbiológica do leite de cabra produzido em Petrolina-PE
}

\author{
Maria Cláudia Soares Cruz Coelho ${ }^{*}$, Benedito Ribeiro Rodrigues ${ }^{1}$, Marcelo Iran de Souza \\ Coelho ${ }^{1}$, Rafael Cunha Libório ${ }^{1}$, Fernanda Fernandes Pinheiro da Costa ${ }^{1}$, Géssica Lopes da \\ Silva ${ }^{1}$
}

\begin{abstract}
RESUMO: Objetivou-se avaliar a qualidade físico-química e microbiológica do leite de cabra produzido em cinco propriedades do município de Petrolina-PE. Realizou-se três coletadas de amostras, em dias distintos, em cada propriedade. Logo após foram realizadas análises físico-químicas, utilizando-se equipamento Master Classic Complete AKSO®, com exceção da acidez, que foi utilizado o método Dornic e, análises microbiológicas de contagem de bactérias aeróbias mesófilas (BAM), número mais provável de coliformes (NMP) totais e termotolerantes. Das 15 amostras analisadas, três apresentaram inadequação quanto ao teor de acidez, nove para índice crioscópico e três para gordura, conforme valores estabelecidos pela legislação. Densidade, proteína, SNG, cinzas e lactose apresentaram médias de $1029,65\left(\mathrm{~g} / \mathrm{cm}^{3}\right) ; 3,22 ; 8,71 ; 0,71 \mathrm{e} ; 4,80(\mathrm{~g} / 100 \mathrm{~g})$, respectivamente. BAM variaram de $5,3 \times 10^{2}$ a $5,3 \times 10^{5}$, onde apenas a propriedade cinco apresentou valor superior ao permitido. Foram identificados coliformes totais em todas as amostras e coliformes termotolerantes apenas nas propriedades um e dois. As amostras de leites de cabras, apresentaram-se fora do estabelecido pela legislação, denotando a necessidade de maior controle por parte dos produtores.
\end{abstract}

Palavras-chave: acidez, coliformes, composição nutricional, densidade, mesófilas.

\section{Physical-chemical and microbiological characteristics of goat's milk produced in Petrolina-PE}

\begin{abstract}
The objective of this study was to evaluate the physical-chemical and microbiological quality of goat milk produced in Petrolina-PE properties. For the physical-chemical analysis, Master Classic Complete Akso ${ }^{\circledR}$ equipment was used, with the exception of acidity, using the Dornic method. Analyzes were performed of counts of mesophilic aerobic bacteria (MAB), most probable number of total coliforms (MPN) and thermotolerant. Three samples presented inadequacy regarding acidity, nine for cryoscopic index and three for fat according to the values established by the legislation. density, protein, NFS, ash and lactose presented averages of 1029.65 (g / cm3); 3.22; 8.71; $0.71 \mathrm{e}$; $4.80(\mathrm{~g} / 100 \mathrm{~g})$, respectively. $\mathrm{MAB}$ ranged from $5.3 \times 10^{2}$ to $5.3 \times 10^{5}$, where only property five was higher than the allowable value. Total coliforms were identified in all samples and thermotolerant coliforms only in properties one and two. Goat milk samples, which were out of compliance with the legislation, show a greater need for control by producers, since they can cause harm to the consumer.
\end{abstract}

Keywords: acidity, coliforms, composição nutricional, density, mesophlilic.

\section{INTRODUÇÃO}

O leite de cabra é o produto oriundo da ordenha completa, ininterrupta, em condições de higiene, de animais da espécie caprina sadios, bem alimentados e descansados, tornando-se um alimento rico nutricionalmente por fornecer nutrientes como minerais, vitaminas, proteínas de fácil digestão, aminoácidos com adequado perfil nutricional e ácido graxo essencial, importantes na maioria das funções do corpo (BRASIL, 2000; DREWNOWSKI, FULGONI, 2008).

De acordo com Pandya, Ghodke (2007), o leite de cabra possui em média 4,25\% de gordura; $3,52 \%$ de proteínas, $4,27 \%$ de lactose, $0,86 \%$ de cinzas, $8,75 \%$ de sólidos não gordurosos (SNG) e $13 \%$ de sólidos totais (ST). No entanto, a proteína e a gordura são de fundamental importância, devido sua contribuição para o rendimento, características sensoriais e sabor dos produtos lácteos (SCINTU,
PIREDDA, 2007). A composição físico-química do leite de cabra foi avaliada por vários pesquisadores (PEREIRA et al., 2005; OLIVEIRA et al., 2005; ANDRADE et al., 2008; ALMEIDA et al., 2009) e pode sofrer variações em função da dieta, raça, idade do animal, estação do ano, temperatura ambiental, estágio de lactação, número de ordenhas diárias e manejo sanitário (TRONCO, 2010; GOETSCH et al., 2011).

Brasil (2000), estabelece requisitos mínimos de qualidade do leite de cabra destinado ao consumo humano, como por exemplo: 13 a $18{ }^{\circ} \mathrm{D}$ para acidez; $2,9 \%$ para gordura; $4,3 \%$ para lactose; $8,2 \%$ de sólidos não gordurosos e 1.028,0 a 1.034,0 g/l para densidade a $15^{\circ} \mathrm{C}$.

$\mathrm{O}$ leite de cabra apresenta densidade mais elevada do que o leite de vaca, podendo atingir $1034 \mathrm{~g} / \mathrm{l}$ e, o teor de acidez apresenta-se 
ligeiramente inferior, variando entre 0,11 e $0,18{ }^{\circ} \mathrm{D}$ (PEREIRA et al., 2005). A densidade é o peso específico do leite e seu resultado depende do teor de partículas em solução e da porcentagem de gordura, neste sentido, esta análise pode detectar adulterações do leite, já que a adição de água causa diminuição da densidade e, a retirada de gordura resulta em aumento da densidade (SILVA et al., 2011). Já a acidez pode ser utilizada como indicador do estado de conservação do leite em função da relação entre disponibilidade de lactose e produção de ácido láctico por ação microbiana, acarretando aumento na acidez e diminuição no teor de lactose.

O teor de gordura total é semelhante ao leite de vaca, em torno de $3,5 \%$, porém, o leite de cabra apresenta menor tamanho dos glóbulos de gordura, resultando em melhor textura dos produtos beneficiados, além de apresentar em sua composição de ácidos graxos, maior proporção de ácidos de cadeia curta e média, tais como o caproico (C6:0), caprílico (C8:0) e cáprico (C10:0), responsáveis pelo odor caprino característico do leite (SILANIKOVE et al., 2010).

Com relação às proteínas do leite, praticamente não existe diferenças entre os leites de cabra e vaca, sendo subdivididas em caseína (80\%) e proteínas do soro (20\%), conforme Tronco (2010). No entanto, apesar de não existir diferenças entre as proteínas do leite de ambas as espécies, Park et al. (2007) relata que o leite de cabra produz um coágulo mais fino do que o leite de vaca após a acidificação, semelhante as condições existentes no estômago, permitindo que seja mais facilmente digerido, podendo ser melhor utilizado por pessoas que sofrem de problemas de acidez, úlcera estomacal e distúrbios digestivos.

$\mathrm{O}$ teor de cinzas ou minerais no leite de cabra pode variar de 0,70 a $0,85 \%$, onde o cálcio e fósforo encontram-se ligados à caseína na forma de um complexo denominado de fosfocaseinato de cálcio, sendo o leite caprino mais rico em cálcio e fósforo, quando comparado ao leite de vaca (SILANIKOVE et al., 2010).

As condições higiênico-sanitárias em que ocorre a ordenha e o armazenamento do leite de origem caprina nas pequenas propriedades do semiárido ainda são ineficazes e, a falta de higiene poderá resultar em perda da qualidade da matéria prima, bem como, seus derivados, levando a prejuízos financeiros pela possível rejeição do produto.

A legislação brasileira estabelece padrões microbiológicos para o leite de cabra cru, somente para contagem global (BRASIL, 2000). Porém, diversos grupos de microrganismos são importantes no monitoramento da qualidade microbiológica dos alimentos (BELTRÃO FILHO et al., 2008), dentre eles pode-se citar as bactérias aeróbias mesófilas e as bactérias do grupo coliforme.

As bactérias aeróbias mesófilas são aquelas capazes de crescer em temperaturas de $35-37^{\circ} \mathrm{C}$ e indicam a qualidade do alimento, uma vez que, estes microrganismos predominam em situações em que há falta de condições básicas de higiene, bem como falta de refrigeração do leite, abrangendo um número significativo de microrganismos patogênicos (FRANCO, LANDGRAF, 2001; BELTRÃO FILHO et al., 2008).

Já os coliformes termotolerantes, conforme Gottardi et al. (2008), são indicadores de contaminação de origem fecal e sua presença pode apresentar riscos de contaminação por microrganismos patogênicos, que podem causar intoxicação alimentar ao consumidor.

Os coliformes totais são compostos por bactérias da família Enterobacteriaceae, capazes de fermentar a lactose com produção de gás, quando incubados a $35-37{ }^{\circ} \mathrm{C}$ por 48 horas (MENDES et al., 2009). Já os coliformes termotolerantes são caracterizados pela sua capacidade de fermentar a lactose com produção de ácido e gás numa temperatura de $45{ }^{\circ} \mathrm{C}$. Estes microrganismos se constituem em um subgrupo dos coliformes totais, onde sua presença indica a probabilidade de contaminação com material de origem fecal (MENDES et al., 2009).

Foi descrito por Rangel et al. (2012) contagem média de mesófilos de 5,122 $\log \mathrm{UFC} / \mathrm{mL}$, valor inferior à contagem máxima (6 log $\mathrm{UFC} / \mathrm{mL}$ ) permitida para o leite bovino cru (BRASIL, 2002).

Com relação à contagem de coliformes totais, Kondyli et al. (2012) e Mhone et al. (2011), observaram médias de $6,9 \times 10^{2} \mathrm{UFC} / \mathrm{mL}$ e $2,5 \times 10^{6}$ $\mathrm{UFC} / \mathrm{mL}$, respectivamente, em condições diferentes de higiene durante a ordenha.

Santos et al. (2012), avaliando a qualidade microbiológica do leite de cabra comercializado na região do Vale do Jaguaribe, CE, observaram que as amostras de leite caprino pasteurizado apresentaram contagens de coliformes totais inferiores a 4,0 NMP $\mathrm{ml}^{-1}$ (variação de $<4,0$ a 3,0 $\mathrm{NMP} \mathrm{ml}^{-1}$ ) e ausência de coliformes termotolerantes.

O resultado das análises de leite cru obtido por Souza et al. (2013) apresentou contagem média de mesófilos inferior à contagem máxima permitida, que é de $5,0 \times 10^{5} \mathrm{UFC} / \mathrm{mL}^{-1}$ na legislação, porém, estas amostras apresentaram presença de Escherichia coli, bactéria de origem fecal.

Diante do exposto e considerando a necessidade de informações acerca da condição do produto, 
objetivou-se avaliar a qualidade físico-química e microbiológica do leite de cabras cru produzido em cinco propriedades no município de Petrolina-PE.

\section{MATERIAL E MÉTODOS}

$\mathrm{O}$ experimento foi realizado em cinco propriedades de base familiar produtoras de leite de cabras, situadas no município de Petrolina-PE, sendo que para cada propriedade coletou-se três amostras em dias distintos, a partir de cabras mestiças de diferentes idades.

O leite total foi ordenhado uma vez ao dia e coletado inicialmente em um Becker de $100 \mathrm{~mL}$ devidamente higienizado e esterilizado, em seguida homogeneizado e transferido assepticamente para frascos estéreis, identificados previamente, dotados de tampa rosqueada. As amostras foram então acondicionadas em caixas de isopor com gelo reciclável e transportadas aos laboratórios para realização das análises.

As análises físico-químicas de gordura, SNG, densidade, proteína, lactose, cinzas, crioscopia e adição de água foram realizadas por medida direta através do equipamento Master Classic Complete AKSO ${ }^{\circledR}$. A acidez foi determinada através da titulação de amostras de leite com solução Dornic $\left({ }^{\circ} \mathrm{D}\right)$, na presença do indicador de fenolftaleína $1 \%$ $(\mathrm{m} / \mathrm{v})$ de acordo com metodologia descrita em Brasil (2006).

Para contagens de bactérias aeróbias mesófilas mediu-se assepticamente $25 \mathrm{~mL}$ das amostras de leites que foram transferidas para frascos contendo $225 \mathrm{~mL}$ de água peptonada $0,1 \%$, obtendo-se a diluição $10^{-1}$. Desta, retirou-se $1 \mathrm{~mL}$ que foi transferido para um tubo de ensaio contendo $9 \mathrm{~mL}$ de água peptonada a $0,1 \%$ para obtenção da diluição $10^{-2}$ e assim sucessivamente até chegar a diluição $10^{-4}$. Alíquotas de $1 \mathrm{~mL}$ das três últimas diluições foram então transferidas para placas de Petri estéreis, vertendo-se nas placas inoculadas o meio Ágar Padrão para Contagem (PCA). As placas foram incubadas a $35^{\circ} \mathrm{C}$ por $24-48$ horas e as colônias formadas foram enumeradas, sendo os resultados expressos como Unidades Formadoras de Colônias/mL (UFC/mL) (SILVA et al., 2010).

As análises dos leites quanto à presença ou não de coliformes totais e termotolerantes, foram realizadas por meio da técnica do Número Mais Provável (NMP/mL), conforme metodologia proposta por Silva et al. (2010). O número de coliformes totais foi realizado pela técnica de tubos múltiplos, utilizando-se o meio de cultura caldo Verde Brilhante Bile Lactose a $2 \%$ (VBBL), onde foram inoculadas alíquotas de $1 \mathrm{~mL}$ das diferentes diluições, $10^{-2}, 10^{-3}$ e $10^{-4}$, em séries de três tubos contendo o meio e, posteriormente, foram incubadas em estufa bacteriológica a $35^{\circ} \mathrm{C}$ por 24 48 horas, considerando-se positivos os tubos de Durham com produção de gás e turvação do meio. Já para a determinação do NMP de coliformes termotolerantes, foram transferidas, com a alça de platina, alíquotas dos inóculos obtidos nos tubos positivos de meio VBBL, para três séries de tubos contendo o meio de cultura caldo Escherichia coli (EC), incubando-se em banho-maria a $44,5{ }^{\circ} \mathrm{C}$ por 24-48 h, os tubos com a produção de gás nos tubos de Durham e turvação do meio foram considerados positivos. Os resultados de NMP para coliformes totais e termotolerantes foram calculados por meio da tabela de NMP de coliformes e expressos em $\mathrm{NMP} / \mathrm{mL}$.

As análises foram realizadas em triplicatas e os dados analisados estatisticamente assumindo o delineamento inteiramente casualizado. Os resultados foram submetidos à análise de variância e as médias analisadas pelo teste de Tukey a 5\% de significância. Os procedimentos estatísticos foram efetuados usando-se o programa Statistical Analysis System (SAS, 2003). Realizou-se também análise estatística descritiva simples com a frequência quantificada como sendo dentro e/ou fora dos padrões, que foram, posteriormente, confrontados à luz da literatura pertinente e com a legislação vigente.cm em largura, e devem ser inclusos sempre com a orientação da página na forma retrato.

\section{RESULTADOS E DISCUSSÃO}

Verifica-se que, as 15 amostras de leite de cabra apresentaram características físico-químicas dentro dos padrões estabelecidos em Brasil (2000), com exceção de três amostras que apresentaram-se inadequadas quanto ao teor de acidez, nove amostras para índice crioscópico e três amostras para gordura (Tabela 1).

Valores elevados da acidez podem ter como justificativa o tempo em que o leite ficou sem tratamento térmico e em temperatura ambiente, desde o período da ordenha até a coleta das amostras (SILVA et al., 2011), uma vez que, acidez elevada pode estar relacionada à produção de ácido lático pelos microrganismos, podendo indicar falta de higiene, demora de tratamento térmico do leite e uma contagem microbiana alta.

As porcentagens de gordura das três amostras de uma das propriedades encontraram-se abaixo do estabelecido pela legislação, podendo ter sido influenciada pela maior produção de leite no início da lactação, uma vez que o conteúdo de gordura é 
inversamente proporcional à quantidade de leite produzido (VENTURINI et al., 2007). Porcentagem de gordura inferior ao requisito mínimo $(2,9 \%)$ pode ser admitida para a variedade de leite integral mediante comprovação de que o teor médio de gordura do determinado rebanho não atinja esse nível (COSTA et al., 2007).

Valores elevados de crioscopia podem estar relacionados à fatores inerentes ao animal, ao leite e ao ambiente, ocasionando dificuldades para o estabelecimento de padrões crioscópicos (PEREIRA et al., 2000).
Observaram-se diferenças estatísticas nos parâmetros físico-químicos em todos as propriedades produtoras de leite de cabra (Tabela 2). Fernandes et al. (2008) e Almeida et al. (2009) relataram que a composição química e as propriedades do leite de cabra podem apresentar variações conforme fatores fisiológicos, genéticos, climáticos e nutricionais, tais como, raça, idade, ciclo estral, estágio da lactação, alimentação, condições ambientais, manejo, estado de saúde do animal, quantidade de leite produzido e fisiologia individual do animal. Estes fatores podem explicar as diferenças encontradas na presente pesquisa.

Tabela 1 - Média geral, variação dos resultados e conformidade com a legislação.

\begin{tabular}{l|l|l|l|l}
\hline Análises & Média geral & Variação dos resultados & $\begin{array}{c}\text { \% de amostras em } \\
\text { conformidade }\end{array}$ & $\begin{array}{c}\text { Requisitos } \\
\text { (BRASIL 2000) }\end{array}$ \\
\hline Densidade $\left(\mathrm{g} / \mathrm{cm}^{3}\right)$ & 1029,65 & 1028,11 a 1033,31 & 100 & 1028,00 a 1034,00 \\
Crioscopia $\left({ }^{\circ} \mathrm{H}\right)$ & $-0,5887$ & $-0,626$ a $-0,560$ & 40 & $-0,550$ a $-0,585$ \\
Acidez $\left({ }^{\circ} \mathrm{D}\right)$ & 17,13 & 14 a 21 & 80 & 13 a 18 \\
Gordura $(\mathrm{g} / 100 \mathrm{~g})$ & 4,26 & 2,75 a 5,79 & 100 & $>2,9$ \\
SNG $(\mathrm{g} / 100 \mathrm{~g})$ & 8,71 & 8,40 a 9,34 & 100 & $>8,2$ \\
Proteína $(\mathrm{g} / 100 \mathrm{~g})$ & 3,22 & 3,09 a 3,43 & 100 & $>2,8$ \\
Lactose $(\mathrm{g} / 100 \mathrm{~g})$ & 4,80 & 4,62 a 5,14 & 100 & $-4,3$ \\
Cinzas $(\mathrm{g} / 100 \mathrm{~g})$ & 0,71 & 0,68 a 0,76 & - \\
\hline
\end{tabular}

Tabela 2 - Características físicas e químicas do leite de cabras.

\begin{tabular}{|c|c|c|c|c|c|}
\hline \multirow[b]{2}{*}{ Análises } & \multicolumn{5}{|c|}{ Propriedades } \\
\hline & 1 & 2 & 3 & 4 & 5 \\
\hline Densidade $\left(\mathrm{g} / \mathrm{cm}^{3}\right)$ & $1028,25^{\mathrm{a}}$ & $1028,30^{\mathrm{a}}$ & $1029,22^{b}$ & $1033,07^{\mathrm{c}}$ & $1029,42^{b}$ \\
\hline Crioscopia $\left({ }^{\circ} \mathrm{H}\right)$ & $-0,598^{\mathrm{b}}$ & $-0,573^{\mathrm{cd}}$ & $-0,590^{\mathrm{bc}}$ & $-0,620^{\mathrm{a}}$ & $-0,563^{\mathrm{d}}$ \\
\hline Acidez $\left({ }^{\circ} \mathrm{D}\right)$ & $17,0^{\mathrm{b}}$ & $17,0^{\mathrm{b}}$ & $20,3^{\mathrm{c}}$ & $15,0^{\mathrm{a}}$ & $16,3^{\mathrm{ab}}$ \\
\hline Gordura $(g / 100 g)$ & $5,76^{\mathrm{e}}$ & $4,78^{\mathrm{d}}$ & $4,66 \mathrm{c}$ & $2,79^{\mathrm{a}}$ & $3,32^{\mathrm{b}}$ \\
\hline SNG $(g / 100 g)$ & $8,69^{b}$ & $8,47^{\mathrm{a}}$ & $8,69^{b}$ & $9,26^{\mathrm{c}}$ & $8,43^{\mathrm{a}}$ \\
\hline Proteína $(\mathrm{g} / 100 \mathrm{~g})$ & $3,23^{\mathrm{b}}$ & $3,14^{\mathrm{a}}$ & $3,22^{\mathrm{b}}$ & $3,40^{\mathrm{c}}$ & $3,10^{\mathrm{a}}$ \\
\hline Lactose $(\mathrm{g} / 100 \mathrm{~g})$ & $4,78^{\mathrm{b}}$ & $4,67^{\mathrm{a}}$ & $4,78^{\mathrm{b}}$ & $5,10^{\mathrm{c}}$ & $4,64^{\mathrm{a}}$ \\
\hline Cinzas $(\mathrm{g} / 100 \mathrm{~g})$ & $0,70^{\mathrm{b}}$ & $0,69^{\mathrm{a}}$ & $0,71^{\mathrm{b}}$ & $0,75^{\mathrm{c}}$ & $0,69^{\mathrm{a}}$ \\
\hline
\end{tabular}

A densidade do leite de cabra in natura variou de 1028,11 a 1033,3 g/L, apresentando-se dentro dos valores estabelecido pela legislação brasileira. Conforme descrito por Oliveira et al. (2005), a densidade do leite está relacionada principalmente com a concentração de elementos dissolvidos em suspensão (SNG) e com a proporção de gordura, e deve oscilar com a variação desses componentes. Resultados semelhantes foram encontrados por Rangel et al. (2012) e Souza et al. (2013), de 1030,0 e $1029,3 \mathrm{~g} / \mathrm{L}$, respectivamente.

Com relação à adição de água, não foi observada em nenhuma das análises, denotando falta de evidencia de fraudes.

A propriedade quatro apresentou ponto de congelamento inferior ao preconizado na legislação. Segundo Henno et al. (2008), o decréscimo em $0,1 \%$ do teor proteico do leite pode resultar em acréscimo de $0,0024{ }^{\circ} \mathrm{C}$ no índice crioscópico.
Neste contexto, a amostra quatro apresentou maior teor de proteína, fato que possivelmente contribuiu para a diminuição do ponto de congelamento dessas amostras.

Com relação à acidez, os valores diferiram estatisticamente entre as propriedades, variando de 15,0 a $20,3{ }^{\circ} \mathrm{D}$, com média de $17,13{ }^{\circ} \mathrm{D}$. Pinto Júnior et al. (2012) observaram uma acidez de 16 ${ }^{\circ} \mathrm{D}$ em leite cru de cabras Saanen. Pinheiro et al. (2014), avaliando as características físico-químicas do leite caprino na época seca e chuvosa na microrregião de Mossoró-RN, verificaram valor médio de acidez de $16,25^{\circ} \mathrm{D}$.

Observou-se diferença estatística entre as propriedades para o parâmetro teor de gordura, com valores médios variando de 2,79 a $5,76 \%$, sendo o maior valor encontrado na propriedade um. Dentre os fatores fisiológicos que afetam a composição e produção do leite, pode- se destacar o estágio de 
lactação dos animais, onde, com o avanço no seu período de lactação há uma tendência de reduzir a produção leiteira, verificando em consequência da queda na produção, um aumento nos seus constituintes, principalmente gordura, fato que pode ter contribuído para os resultados encontrados. Andrade et al. (2008) e Santos et al. (2012) verificaram teor de gordura médio de 3,7 e 3,63\%, respectivamente, portanto, inferior ao valor médio encontrado no leite dos animais da presente pesquisa, que foi de 4,26\%. Valor semelhante foi verificado por Pinheiro et al. (2014), que descreveram valor médio de $4,2 \%$. No tocante ao SNG, verifica-se diferença estatística entre as propriedades produtoras de leite de cabra, podendose evidenciar que a propriedade que mostrou menor valor para SNG $(8,43 \%)$ decorre, sobretudo, da redução do nível de proteína do leite $(3,10 \%)$. Porém, todas as amostras de SNG apresentaram-se em acordo com o estabelecido pela legislação (BRASIL, 2000), com valores variando de 8,43 a 9,26\% (Tabela 2). Pinto Júnior et al (2012) constaram em leite de cabras da raça Saanen, valores de SNG variando de 8,54 a $8,82 \%$. Santos et al. (2012), estudando os SNG de leite caprino comercializado na região do vale do Jaguaribe Ceará, observaram variação de 6,76 a $10,21 \%$, com valor médio de $8,55 \pm 1,29 \%$, portanto, valores semelhantes aos verificados no presente trabalho, lembrando que estes podem variar de acordo com fatores como raça, clima e tempo de lactação.

Os valores de proteína das amostras coletadas por propriedades variaram de 3,10 a $3,40 \%$, portanto, acima do preconizado na legislação brasileira (acima de 2,8\%) e superior aos resultados verificados por Silva et al. (2011) e Pinheiro et al. (2014), que foram de 2,90 e 2,85\%, respectivamente. Assim como a gordura, a proteína do leite pode ser influenciada pela raça, estágio de lactação, alimentação, clima, número de partos, época do ano, e estado de saúde do úbere (MENDES et al., 2009).

Verificou-se que estatisticamente as amostras de leite de cabra de cada propriedade foram diferentes para o parâmetro lactose, com valor médio de 4,8\% e destaque para propriedade quatro, que apresentou valor de $5,10 \%$. Este resultado pode estar relacionado com maior produção leiteira dos animais e menor teor de gordura da amostra. Andrade et al. (2008) encontraram teor de lactose médio, correspondendo a $4,5 \pm 0,33 \%$, ao analisarem leite de cabra pasteurizado. Santos et al. (2012) verificaram valores variando de 4,12 a 4,94\%. Avaliando a qualidade físico-química de leite de cabras em torneios leiteiros, Rangel et al. (2012) observaram valor médio de lactose de $4,89 \%$.

Os teores de cinzas variaram de 0,68 a $0,76 \%$, com média de $0,71 \%$. Oliveira et al. (2005) encontraram teor de cinzas variando de 0,64 a $0,92 \%$. Santos et al. (2012) verificaram variação de 0,67 a 0,89 . Park et al. (2007) revisou a quantidade de minerais do leite de diferentes espécies e afirmou que o leite de cabra, em comparação ao leite de vaca, fornece maior quantidade (mg/100 $\mathrm{g}$ de leite) de $\mathrm{Ca}, \mathrm{P}, \mathrm{K}, \mathrm{Mg}$ e $\mathrm{Cl}$, e os mais baixos de $\mathrm{Na}$ e enxofre.

Os padrões microbiológicos do leite de cabra cru são estabelecidos no Regulamento Técnico $\mathrm{N}^{\circ} .37$ do Ministério da Agricultura que trata da produção, identidade e qualidade do leite de cabra, atualmente em vigor (BRASIL, 2000).

Os resultados da contagem de bactérias aeróbias mesófilas, número mais provável de coliformes totais e termotolerantes do leite de cabra cru produzido em propriedades no município de Petrolina-PE estão apresentados na Tabela 3.

Tabela 3 - Análises microbiológicas do leite de cabra cru.

\begin{tabular}{lccc}
\hline Propriedades & $\begin{array}{c}\text { Contagem de bactérias } \\
\text { mesófilas }(\text { UFC/mL) }\end{array}$ & NMP de coliformes totais $(\mathrm{NMP} / \mathrm{mL})$ & $\begin{array}{c}\text { NMP de coliformes } \\
\text { termotolerantes }(\mathrm{NMP} / \mathrm{mL})\end{array}$ \\
\hline 1 & $5,3 \times 10^{2}$ & $>1100$ & $>1100$ \\
2 & $2,7 \times 10^{4}$ & 43 & 15 \\
3 & $2,2 \times 10^{5}$ & 75 & $<3,0$ \\
4 & $2,9 \times 10^{3}$ & 9,2 & $<3,0$ \\
5 & $5,3 \times 10^{5}$ & $>1100$ & $<3,0$ \\
\hline
\end{tabular}

Os valores encontrados para bactérias aeróbias mesófilas variaram de $5,3 \times 10^{2}$ a $5,3 \times 10^{5}$, verificando-se que apenas a propriedade cinco apresentou uma contagem média de mesófilo superior à contagem máxima permitida, que é de 5,0 x $10^{5} \mathrm{UFC} / \mathrm{mL}$ (BRASIL, 2000). Segundo Mendes et al. (2009), bactérias aeróbias mesófilas são verificadas em maior número, em geral, em situações onde há falta de condições básicas de higiene. Também se deve considerar que todas as bactérias patogênicas de origem alimentar são mesófilas, neste caso, contagem elevada desse grupo pode significar que houve problemas na conservação e/ou refrigeração do leite, criando condições para o crescimento de patógenos (FRANCO, LANDGRAF, 2001). Tanto a falta de higiene durante a ordenha, 
como a demora na refrigeração do leite podem ter contribuído para as altas contagens de bactérias aeróbias mesófilas nas amostras, principalmente, nas amostras coletadas na propriedade cinco.

Araújo et al. (2007) analisando duas mini usinas de leite de cabra no estado da Paraíba obtiveram como média para microrganismos mesófilos respectivamente $7,4 \times 10^{9}$ e $6,1 \times 10^{9} \mathrm{NMP} / \mathrm{mL}$. Portanto, bastante superior aos resultados desta pesquisa. Foi observado por Santos et al. (2012) que as amostras de leite caprino pasteurizado, provenientes da região do Vale do Jaguaribe, apresentaram contagem de bactérias mesófilas variando de $1,1 \times 10^{3}$ a $4,3 \times 10^{4} \mathrm{UFC} \mathrm{ml}^{-1}$. Santos et al (2013) verificaram valores de bactérias aeróbias mesófilas de $1,15 \times 10^{5} 1,16 \times 10^{5}$ e $1,18 \times 10^{5}$.

Foram identificados coliformes totais em todas as amostras analisadas, com valores variando de 9,2 a $>1100 \mathrm{NMP} / \mathrm{mL}$. Com relação aos coliformes termotolerantes, foram encontrados apenas nas propriedades um e dois (Tabela 3). A presença de bactérias do grupo coliformes nas amostras analisadas pode indicar a existência de contaminação do leite, contudo, não há na legislação brasileira padrões para contagem de coliformes totais e termotolerantes.

Considerando que a pasteurização destrói em torno de $98 \%$ dos micro-organismos do leite, a quantidade de coliformes totais e termotolerantes no leite de cabra cru deveria ser de $133 \mathrm{NMP} / \mathrm{mL}$ e 33 $\mathrm{NMP} / \mathrm{mL}$, respectivamente, para que após a pasteurização o leite encontre-se dentro dos limites estabelecidos para no máximo $4 \mathrm{NMP} / \mathrm{mL}$ para coliformes totais e entre $1-2 \mathrm{NMP} / \mathrm{mL}$ para coliformes termotolerantes.

Segundo Andrade et al. (2008), pesquisa de bactérias do grupo dos coliformes é importante pela sua relação com a higiene durante a produção e, sua presença é considerada como indicador de condições insatisfatórias durante a produção de alimentos, podendo ser indicadores de contaminação ambiental e fecal.

Valores elevados de coliformes termotolerantes verificados nas amostras coletadas nas propriedades um e dois, podem ser explicados pelas condições em que o produto foi obtido, uma vez que as dependências onde se realizam as ordenhas não encontravam-se dentro dos padrões higiênicos e sanitários, principalmente, pelas inadequadas condições de infraestrutura, limpeza do ambiente e higiene dos utensílios e do ordenhador.

Gottardi et al. (2008) ao analisarem o leite de cabra de oito propriedades na região do Vale do Taquari - RS, constataram valores de coliformes totais variando de zero a $1,4 \times 10^{6} \mathrm{UFC} / \mathrm{mL}^{-1}$, já com relação aos coliformes termotolerantes, observaram que apenas duas propriedades apresentaram a presença deste grupo de bactérias, com valores de $3,4 \times 10^{4} \mathrm{UFC} \mathrm{mL}^{-1} \mathrm{e} 4,1 \times 10^{4} \mathrm{UFC} \mathrm{mL}^{-1}$.

Ao avaliar 15 amostras de leite de cabra antes e após o envase, Andrade et al (2008) verificaram que apenas três amostras de leite cru apresentaram coliformes totais no teste presuntivo, sendo confirmado pela semeadura em ágar Levine e, entre estas, apenas uma amostra apresentou resultado positivo para coliformes termotolerantes $(0,4 \mathrm{NMP}$ $\left.\mathrm{mL}^{-1}\right)$.

Souza et al. (2013) averiguaram valores de coliformes totais e termotolerantes de $>1100$ e 150 $\mathrm{NMP} / \mathrm{mL}$, respectivamente, em três lotes de leite de cabra cru adquiridos no município de Alfenas-MG, portanto, valores bastante superiores aos verificados no presente experimento.

Valores inferiores foram reportados por Santos et al. (2012) em amostras de leite caprino pasteurizado, onde apresentaram contagens de coliformes totais inferiores a 4 NMP ml ${ }^{-1}$ (variação de $<4$ a 3 NMP $\mathrm{ml}^{-1}$ ) e ausência de coliformes termotolerantes, demonstrando que a pasteurização consiste num processo importante de melhoria da qualidade microbiológica do leite. Embora a legislação brasileira não estabeleça padrões máximos de coliformes totais e termotolerantes podem ser utilizados os critérios microbiológicos para leite pasteurizado, conforme descrito em BRASIL (2000).

\section{CONCLUSÕES}

O leite de cabra in natura, produzido em cinco propriedades no município de Petrolina-PE, apresentou, características físico-químicas satisfatórias, com exceção dos parâmetros gordura, índice crioscópico e acidez em algumas amostras. As análises microbiológicas demonstram elevados valores de bactérias em algumas amostras, denotando a necessidade de maior controle por parte destes produtores, a fim de obter um leite que atenda a todos os requisitos de qualidades físico-químicas e microbiológicas estabelecidos pela legislação.

Isso não é conclusão, é discussão

\section{REFERÊNCIAS}

ALMEIDA, J. F.; LEITÃO, C. H. S.; NASCIMENTO, E. R.; VIEIRA, K. C. M.; ALBERTO, E. M. \& PEREIRA, V. L. A. Avaliação físico-química do leite de cabra in natura em alguns rebanhos de Minas Gerais e Rio de Janeiro, Brasil. Ciência Animal Brasileira, p.749-753 (supl. 1), 2009.

ANDRADE, P. V. D.; SOUZA, M. R.; PENNA, C. F. A. M. \& FERREIRA, J. M. Características microbiológicas e físico-químicas do leite de cabra submetido à pasteurização lenta pós-envase e ao congelamento. Ciência Rural, v.38, n.5, p.1424-1430, 2008. 
ARAÚJO, V. J. A.; FERNANDES, A. R. F.; LEITE, H. R.; MEDEIROS, J. M. A.; DANTAS, E. S.; SOUZA, D. R. M.; NARDELLI, M. J. \& CARVALHO, M. G. X. Qualidade do leite de cabra in natura processado em miniusinas do cariri e médio sertão paraibano - Estudo comparativo. Revista do Instituto Laticinista Candido Tostes, v.62, n.357, p.430-436, 2007.

BELTRÃO FILHO, E. M.; COSTA, R. G.; QUEIROGA, R. C. R. E.; MEDEIROS, A. N.; OLIVEIRA, C. J. B.; ROCHA, J. K. P. \& SANTOS, J. G. Avaliação higiênicosanitária do leite de cabra comercializado no estado da Paraíba, Brasil. Revista Brasileira de Saúde e Produção Animal, v.9, n.4, p.672-679, 2008.

BRASIL, Ministério da Agricultura, Pecuária e Abastecimento. Métodos Analíticos Oficiais FísicoQuímicos, para Controle de Leite e Produtos Lácteos (Instrução Normativa ${ }^{\circ}$ 68, de 12 de dezembro de 2006). Diário Oficial da União, 2006.

BRASIL, Ministério da Agricultura, Pecuária e Abastecimento. Regulamento Técnico de Produção, Identidade e Qualidade do Leite de Cabra (Instrução Normativa $\mathrm{n}^{\mathrm{o}}$ 37, de 31 de outubro de 2000). Diário Oficial da União, 2000.

COSTA, R. G., BELTRÃO FILHO, E. M., QUEIROGA, R. C. R. E., MEDEIROS, A. N., OLIVEIRA, C. J. B., \& GUERRA, I. C. D. Características físico-químicas do leite de cabra comercializado no estado da Paraíba, Brasil. Revista Instituto Adolfo Lutz, v.66, n.2, p.136-141, 2007.

DREWNOWSKI, A., \& FULGONI, V. Nutrient profiling of foods: creating a nutrient rich food index. Nutrition Reviews, v.66, n.1, p.23-39, 2008.

FERNANDES, M. F., QUEIROGA, R. C. R. E., MEDEIROS, A. N., COSTA, R. G., BONFIM, M. A., \& BRAGA, A. A. Características físico-químicas e perfil lipídico do leite de cabras mestiças Moxotó alimentadas com dietas suplementadas com óleo de semente de algodão ou de girassol. Revista Brasileira de Zootecnia, v.37, n.4, p.703-710, 2008.

FRANCO, B. D. G. M.; \& LANDGRAF, M. Microbiologia dos alimentos. (1. ed.). São Paulo: Atheneu. 2001.

GOETSCH, A. L., ZENG, S. S., \& GIPSON, T. A. Factors affecting goat milk production and quality. Small Ruminant Researchl, v.111, n.1, p.55-63, 2011.

HENNO, M., OTS, M., JÕUDU, I., KAART, T., \& KÄRT, O. Factors affecting the freezing point stability of milk from individual cows. International Dairy Journal, v.18, n.1, p.210-215, 2008.

GOTTARDI, C. P. T.; MURICY, R. F.; CARDOSO, M.; SCHMIDT, V. Qualidade higiênica de leite caprino por contagem de coliformes e estafilococos. Ciência Rural, v.38, n.3, p.743-748, 2008.

KONDYLI, E.; SVARNAS, C.; SAMELIS, J.; KATSIARI, M. C. Chemical composition and microbiological quality of ewe and goat milk of native Greek breeds. Small Ruminant Research, v.103, n.1, p.194-199, 2012.

MENDES, C. G., SILVA, J. B. A., \& ABRANTES, M. R. Caracterização organoléptica, físico-química, e microbiológica do leite de cabra: uma revisão. Acta Veterinaria Brasilica, v.3, n.1, p.5-12, 2009.

MHONE, T. A.; MATOPE, G.; \& SAIDI, P. T. Aerobic bacterial, coliform, Escherichia coli and Staphylococcus aureus counts of raw and processed milk from selected small holder dairy farms of Zimbabwe. International Journal of Food Microbiology, v.151, n.1, p.223-228, 2011.

OLIVEIRA, M. A., FÁVARO, R. M. D., OKADA, M. M., ABE, L. T., \& IHA, M. H. Qualidade físico-química e microbiológica do leite de cabra pasteurizado e ultra ulta temperatura, comercializado na região de Ribeirão PretoSP. Revista Instituto Adolfo Lutz, v.64, n.1, p.104-109, 2005.

PANDYA, A. J., \& GHODKE, K. M. Goat and sheep milk products other than cheeses and yoghurt. Small Ruminant Research, v.68, n.1, p.193-206, 2007.

PARK, Y. W., JUAREZ, M., RAMOS, M., \& HAENLEIN, G. F. W. Physicochemical characteristics of goat and sheep milk. Small Ruminant Research, v.68, n. 1, p.88-113, 2007.

PEREIRA, D. B. C., OLIVEIRA, L. L., COSTA JÚNIOR, L. C. G., \& SILVA, P. H. F. Físico-química do leite e derivados - Métodos Analíticos. (2. ed.). Juiz de Fora: Oficina de Impressão Gráfica e Editora. 2000.

PEREIRA, R. Â. G., QUEIROGA, R. C. R. E., VIANNA, R. P. T., \& OLIVEIRA, M. E. G. Qualidade química e física do leite de cabra distribuído no Programa Social "Pacto Novo Cariri" no Estado da Paraíba. Revista do Instituto Adolfo Lutz, v.64, n.2, p.205-211, 2005.

PINHEIRO, J. G., AROUCHA, E. M. M., ABRANTES, M. R., FIGUEREDO, J. P., GÓIS, V. A., \& SILVA, J. B. A. Características físico-químicas do leite caprino na época seca e chuvosa na microrregião de Mossoró-RN. Acta Veterinaria Brasilica, v.8, n.3, p.192-200, 2014.

PINTO JÚNIOR, W. R., FERRÃO, S. P. B., RODRIGUES, F. L., FERNANDES, S. A. A., \& BONOMO, P. Efeito do congelamento sobre os parâmetros físico-químicos do leite de cabras da raça Saanen. Revista Caatinga, v.25, n.3, p.110-117, 2012.

RANGEL, A. H. N., PEREIRA, T. I. C., ALBUQUERQUE NETO, M. C., MEDEIROS, H. R., 
ARAÚJO, V. M., NOVAIS, L. P., ABRANTES, M. R., \& LIMA JÚNIOR, D. M. Produção e qualidade do leite de cabras de torneios leiteiros. Arquivos do Instituto Biológico, v.79, n.2, p.145-151,2012.

SANTOS, D. C., MARTINS, J. N., OLIVEIRA, E. N. A., \& FALCÃO, L. V. Caracterização de leite caprino comercializado na região do Vale do Jaguaribe, Ceará. Revista Verde, v.7, n.2, p.289-295, 2012.

SAS Institute. SAS/STAT software: Changes and enhancements through release 6.12. cary: Statistical Analysis System institute. 2003.

SCINTU, M. F., \& PIREDDA, G. Typicity and biodiversity of goat and sheep milk products. Small Ruminant Research, v.68, n.1, p.221-231, 2007.

SILANIKOVE, N., LEITNER, G., MERIN, U., \& PROSSER, C. G. Recent advances in exploiting goat's milk: Quality, safety and production aspects. Small Ruminant Research, v.89, n.1, p.110-124, 2010.

SIlVA, J. N., ARAÚJO, A. C., SANTOS, E. P., HOLANDA NETO, J. P., \& ALVES, T. T. L. Parâmetros e determinantes da qualidade físico-química do leite caprino. Revista Verde, v.6, n.3, p.32-38, 2011.
SILVA, N; JUNQUEIRA, V. C. A.; SILVEIRA, N. F. A.; TANIWAKI, M. H.; SANTOS, R. F. S.; GOMES, R. A. R.; OKAZAKI, M. Manual de métodos de análise microbiológica de alimentos. (4. ed.). São Paulo: Varella. 2010.

SOUZA, A. K., FIORINI, J. E., MORAES, A. L. L., OLIVEIRA, N. M. S., CLARETO, S. S., \& NASCIMENTO, L. C. Características microbiológicas e físico-químicas do leite de cabra submetido à pasteurização e ao congelamento, comercializado na cidade de Alfenas-MG. Revista da Universidade Vale do Rio Verde, v.11, n.1, p.224-233, 2013.

VENTURINI, K. S., SARCINELLI, M. F., \& SILVA, L. C. Características do leite. (1. ed.). Vitória: UFES/PróReitoria de Extensão. 2007.

TRONCO, V. M. Manual para inspeção da qualidade do leite. (4. ed.). Santa Maria: UFSM. 2010. 